\title{
Analysis of cyclists' behaviour on different infrastructure elements
}

\author{
Katarzyna Cieśla ${ }^{1}$, Tomasz Krukowicz ${ }^{2, *}$, and Krzysztof Firląg ${ }^{2}$ \\ ${ }^{1}$ Siemens Sp. z o. o., Mobility Sector \\ ${ }^{2}$ Warsaw University of Technology, Faculty of Transport, ul. Koszykowa 75, 00-662 Warsaw
}

\begin{abstract}
Increasing bicycle traffic causes the occurrence of related phenomena, which were not observed before. However, it can be observed that the cycling infrastructure of Warsaw is used in various ways, and some cyclists do not respect the law. The aim of this article is to examine the behaviour of cyclists in various road traffic situations. Empirical research was carried out for 15 objects located in Warsaw. Selected facilities were divided into 7 types of road infrastructure. The research was carried out by means of video recording with the use of a camera. Cyclists were classified by age, gender and type of bike used. As a result of the study, the number of correct and incorrect behaviours of cyclists was determined. It was found that the largest share of prohibited behaviours occurs in case of complicated solutions of cycling infrastructure and in case of its discontinuity. The behaviour of cyclists during the red signal display was also assessed. It was noted that this signal is better respected at road crossings than at tram crossings. Case studies have also been carried out and opportunities for improvement identified.
\end{abstract}

\section{Introduction}

In recent years a significant increase in cycling can be observed. Along with the increase in traffic intensity, numerous abnormal behaviours of cyclists can be observed which may impact road safety. The cycling infrastructure itself is often misused. Similar problems are observed in other countries. Therefore, numerous studies related to cyclists' behaviour are carried out around the world [1-5]. At the end of 2016 in Warsaw there were almost 500 $\mathrm{km}$ of cycling infrastructure [6]. It is planned to expand significantly in the coming years [7]. Therefore, also in Warsaw a research on cyclists' behaviour was conducted $[8,9]$. The results indicate that there is a significant problem which is not recognised. The aim of this article is to present the behaviour of cyclists on various elements of the infrastructure intended for cycling and in various road traffic situations. The further goal is to present the likely reasons of such behaviours and propose solutions to eliminate them.

\footnotetext{
* Corresponding author: tkr@wt.pw.edu.pl
} 


\section{Research}

The research was carried out in Warsaw. It was made by video recording with the use of a sports camera. Its small size made it possible to place oneself in such a way that the observer did not attract attention of the participants of the movement, that could affect their behaviour. The research was carried out at various times of the day and on days of week. The minimum sample number of cyclists was assumed to be 25 , but for most of the facilities the number was greater than 50 .

The regulations in force in Poland [10] divide people cycling into the following groups:

- children under 10 years of age,

- persons caring for children under 10,

- other cyclists.

Different behaviour, in particular as regards the use of different infrastructure and the crossing of roadways, is acceptable or unacceptable depending on the groups mentioned above.

During the study, cyclists were classified according to the following factors: age ( 5 categories), gender, type of bike used (4 categories: public bikes, mountain bikes and city bikes, road bikes, other bikes) and helmet use.

The basic legal act regulating the issues of road marking for bicycles in Poland is [11]. More detailed guidelines also apply in the area of the capital city of Warsaw [12]. Infrastructure solutions designed in various years, both during the period of validity of the guidelines [12] as well as earlier, were selected for the research. The facilities were described as at the end of third quater 2016.

\subsection{Pedestrian and bicycle routes}

The tests were carried out on two roads for pedestrians and bicycles. The first one was a road along the Sikorski Avenue. This road is led on one side of the street. It is characterised by an uneven asphalt surface. This road ends and starts again at the intersections with the exits to the property. Pedestrian crossings are marked out in these areas. For further analysis, the road will be marked as object 1.

Another road studied for pedestrians and cyclists is the one along Żwirki i Wigury Street. It is located near to from a large cycling generator - Pole Mokotowskie Park. An asphalt pavement of good quality was used on the road (object 2).

\subsection{Bicycle lanes}

Three objects with bicycle lanes were tested. The first of them was the entrance to the bicycle lane from the road for bicycles to Świętokrzyska Street, at the intersection with Emilii Plater Street. The entrance to the cycling lane is at the exit of the intersection (object 3).

Another place where the research was carried out is the bicycle lane along Świętokrzyska Street at the intersection with Jasna Street. At the western approach of this crossroads, the traffic of cyclists was controlled by the S-6 signal which was built before the introduction of the amendment [13], which provided for the use of three-aspect traffic lights in such cases. The permit signal for cyclists ends earlier than for the vehicles, due to the longer intergreen times (object 4 - fig. 1). 


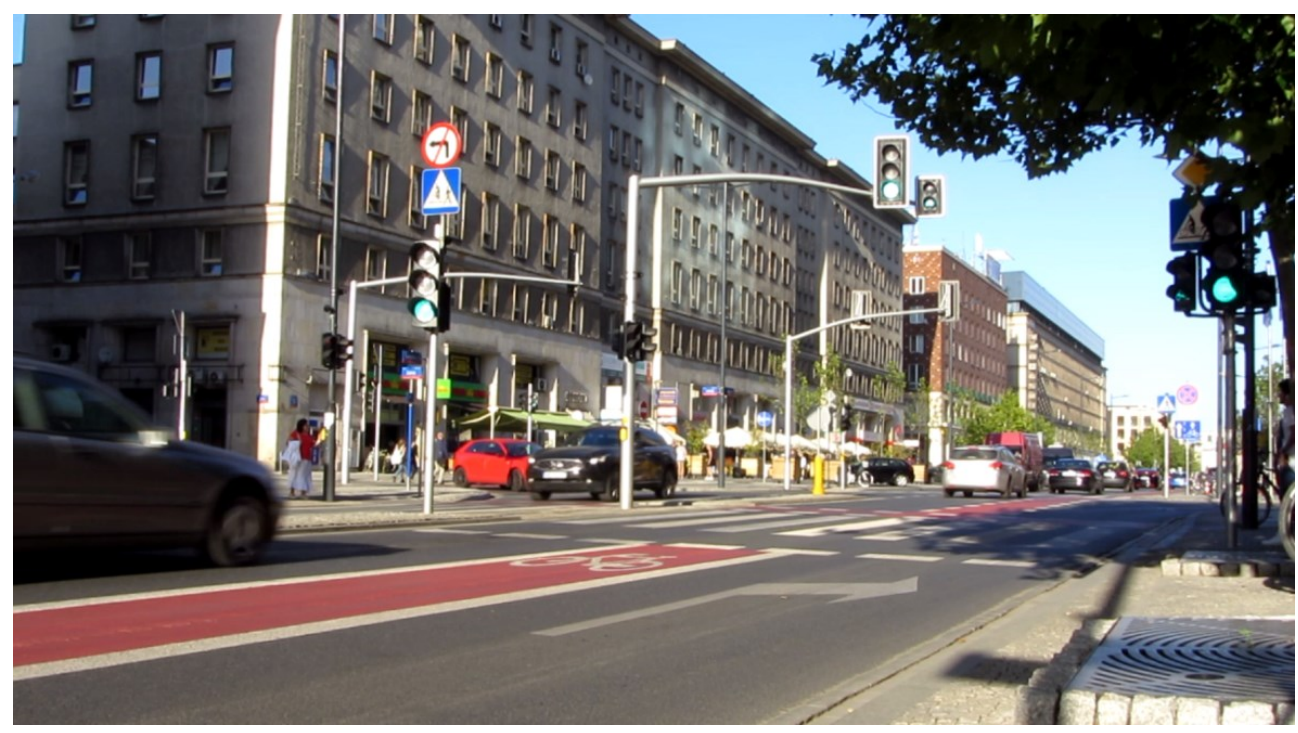

Fig. 1. Bicycle lane along Świętokrzyska Street at the intersection with Jasna Street (object 4).

Another place covered by the research is the bicycle belt along Koszykowa Street at the intersection with Lindleya Street. It ends before a controlled intersection where there are no traffic signals for cyclists. At the approach with the bicycle belt there is a signal S-2 right turn on red (object 5).

\subsection{Bicycle crossings}

Four bicycle journeys were tested. The first one was a bicycle ride through Ciszewskiego Street at the intersection with the Komisji Edukacji Narodowej Avenue (South-Western approach). The width of the crossing is $3 \mathrm{~m}$. The green signal for cyclists started and ended at the crossing of both roadways at Ciszewskiego Street at the same time (object 6).

Another object examined was a bicycle ride at the crossroads of Wołoska Street and Woronicza Street. Cyclists cross 2 roadways and a tramway track here, riding three separate bicycle crossings. At this intersection, the green signals at the bicycle crossings start and end at different times (object 7).

The research was also carried out on a bicycle ride through the entrance to the Imielin housing estate from Komisji Edukacji Narodowej Avenue. This intersection is an uncontrolled intersection, the cycling route is separated from the pavement by a belt of greenery (object 8).

The last bicycle crossing to be studied is the one through Żwirki i Wigury Street at the intersection with Banacha Street. Żwirki i Wigury Street is a two carriageway street with a width of $17 \mathrm{~m}$, which is the distance between the subsequent passages. The green signals for cyclists are of different lengths at the individual crossings (object 9).

\subsection{Roads for bicycles}

The tests were carried out on two bicycle roads. The first one is the road for bicycles along the Komisji Edukacji Narodowej Avenue in the area of Ciszewskiego Street. The road is located directly on the pavement, and there are bicycle crossings within it (object 10). 
Another facility is the road for bikes in the Pole Mokotowskie Park. The tests were carried out at the point of crossing the road with a pedestrian track. The road is bidirectional, made of cobblestone (object 11).

\subsection{Opposite direction bicycle lanes}

The research was carried out only in Mokotowska Street. Attempts to conduct the tests on other objects did not allow to obtain a satisfactory number of tests due to the low traffic intensity of cyclists. The investigated opposite direction bicycle lane is $1.5 \mathrm{~m}$ wide and it is possible to park it in parallel along it. It was observed that many cases of diagonal parking limit the width of the lane available for cyclists (object 12).

\subsection{Advanced stop line}

The measurements were made for the advanced stop line at the intersection of Świętokrzyska Street from Nowy Świat Street. The tested advanced stop line is located at the western approach of the crossroads and allows the cyclists to turn left in the direction of the University of Warsaw. An analogous advanced stop line is also located at the opposite approach. There are bicycle lanes on both sides of Świętokrzyska Street (object 13 - fig. 2).

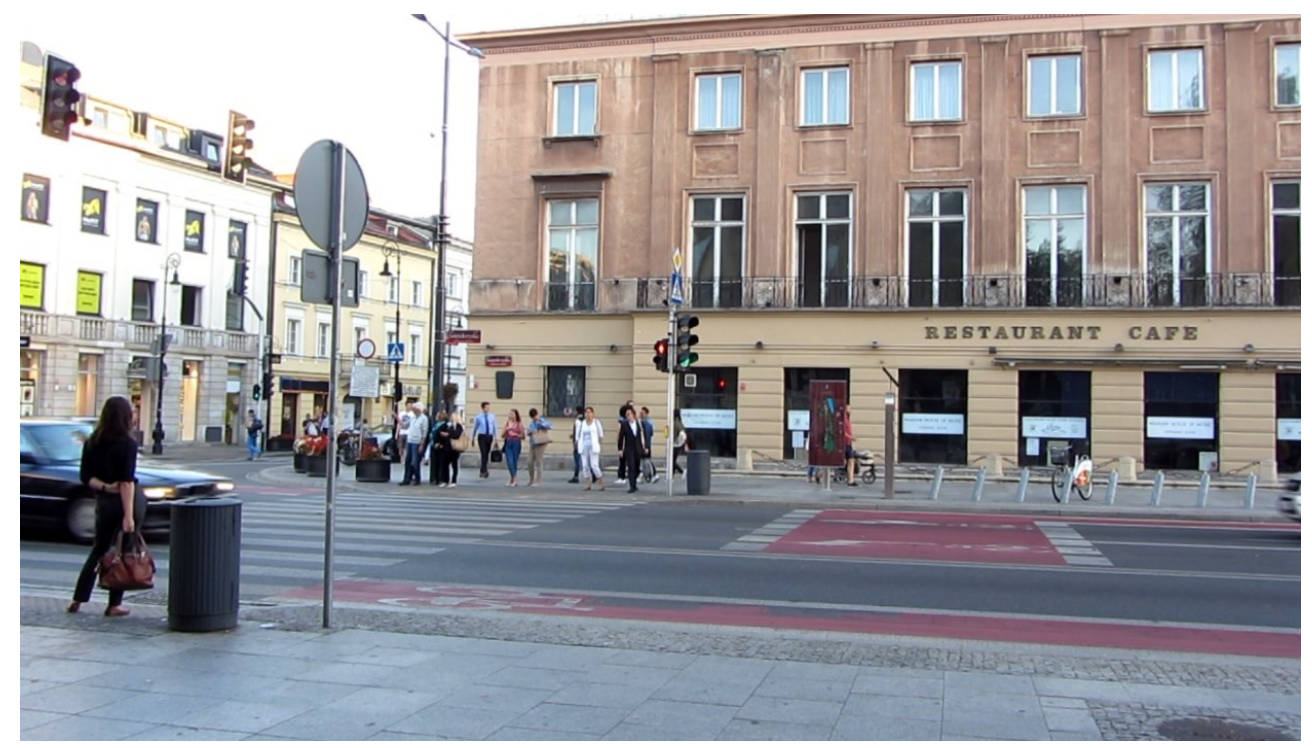

Fig. 2. Advanced stop line at the crossroad of Świętokrzyska Street and Nowy Świat Street (object 13).

\subsection{Pedestrian crossings}

Pedestrian crossings are not an infrastructure for cyclists, but studies have been carried out in two places where bicycle routes are not far away.

The measurements were made at the crossing for pedestrians through Grójecka Street at the intersection with Banacha Street. Immediately before the pedestrian crossing, the bicycle route along Banacha Street, leading from Żwirki i Wigury Street, ends. For this reason, there is a high level of cycling at the crossing (object 14). 
Another investigated place is the pedestrian crossing at the crossroads of Wołoska Street and Domaniewska Street. On both sides of this crossing there are roads for bicycles, but they are located on opposite sides of Wołoska Street, so cyclists must cross both Wołoska Street and Domaniewska Street. Cycling trips are located only at the northern and eastern approaches of the intersection. However, many cyclists do not wait for the signal to pass, but pass through the pedestrian crossings located at the western and southern approaches (object 15).

\section{Test results}

During the research, 2785 cyclists were registered as riding on the 15 described infrastructure facilities. Most of the objects were surveyed once. Measurements on bicycle lanes in Koszykowa Street (facility 5) were carried out on different days of the week (5ameasurement on Tuesdays, $5 \mathrm{~b}$ - measurement on Sundays). In the case of the cycling opposite direction bicycle lane in Mokotowska Street (facility 12), the tests were conducted during the period of high car traffic (12a) and low traffic (12b). The tests of the advanced stop line (facility 13) were carried out during the traffic shutdown period for cars in Nowy Świat Street (13a), as well as during the period when the traffic was allowed (13b).

\subsection{Behaviour of cyclists}

On the basis of the analysis of the recordings for each of the objects, a catalogue of cyclists' behaviour was prepared. These behaviours were then classified as compliant or noncompliant. In some cases it was necessary to distinguish additional behaviours, analyzed regardless of the cyclist's mobility, such as holding a mobile phone in hand. Selected recorded behaviour of cyclists is:

- walking with bicycle through the pedestrian crossing,

- riding a pedestrian crossing,

- entering the cycling lane from the bicycle path,

- entering the cycling lane from the pavement,

- entering the cycling lane from the roadway,

- handheld driving with a mobile phone,

- entry during the green signal,

- entry during the flashing green signal,

- entry during the red signal for cyclists and green signal for vehicles,

- entry during the red signal for cyclists and vehicles,

- bicycle lane operation,

- entry into the pavement before the intersection,

- pavement operation,

- driving on the carriageway,

- no stop in front of the S-2 signal displaying the right turn on red signal,

- no signalling of a turning manoeuvre,

- crossing with the bicycle after the bicycle crossing,

- the exit from the carriageway to the bicycle crossing,

- cycling when the red signal is displayed and the green signal when the other bicycle crossings are displayed,

- $\quad$ riding at pedestrian crossing when red signal is displayed,

- riding at pedestrian crossing when green signal is displayed,

- crossing of the road with a pedestrian track is not handled with care,

- pushing the bicycle on the pavement,

- pushing the bicycle along the way for the bicycle, 
- opposite direction bicycle lane riding in the designated direction of cyclists' movement,

- opposite direction bicycle lane riding contrary to the direction of traffic indicated for cyclists,

- waiting for the green signal in the advanced stop line before straight ahead travel,

- waiting for the green signal in the advanced stop line before driving to the left,

- waiting for the green signal in front of the advanced stop line,

- while waiting for the green signal, enter the pavement and continue driving on the pavement.

\subsection{Assessment of cyclists' behaviour}

For each object, the cyclists' compliance behaviour has been analysed in detail [10]. If this was visible, the report of the cyclist's movement was also recorded, which made it possible to make assumptions about the causes of some behaviours. It was found that the share of public bicycles in Veturilo was only $6.8 \%$ of the population. The total share of women in the study was $35.5 \%$, and $17.7 \%$ of cyclists were in helmets. The highest number of registered cyclists was in the 18-40 age group (68.8\%), although the assessment of age is very erroneous, with tests on individual facilities ranging from 25 (object 12 - second measurement) to 287 (object 13 - second measurement). The share of abnormal behaviours registered in particular objects is shown in Figure 3.

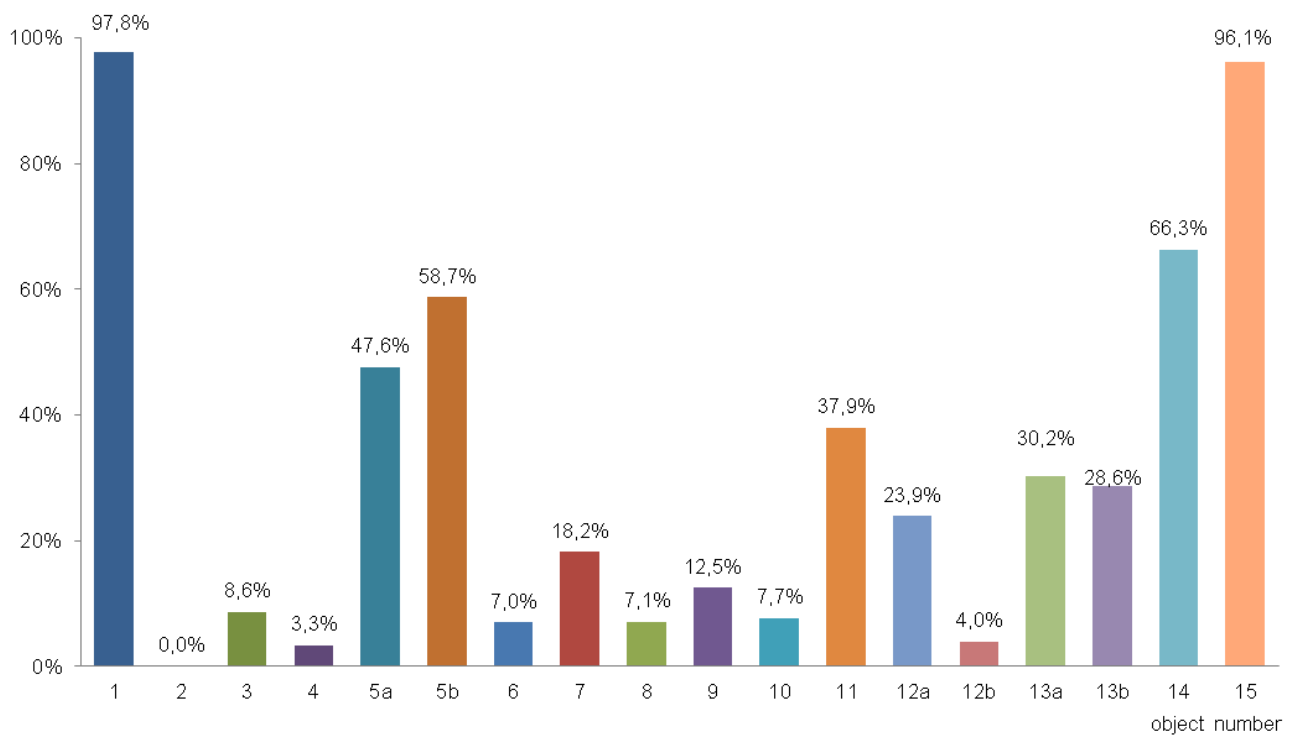

Fig. 3. Percentage of incorrect behaviour of cyclists depending on the type of cycling infrastructure.

The largest share of abnormal behaviour was recorded in objects $1,14,15$, which are places where the cycling route is interrupted or ends with pedestrian crossings. In these places cyclists used to pass through pedestrian crossings. A large share of abnormal behaviour can be observed in the case of facilities $5,11,12,13$.

In the case of object 5 (bicycle belt in Koszykowa Street) a large number of cyclists using the pavement were observed. This is due to the interruption of the cycling lane at the intersection. Many people also did not report a right turn manoeuvre at the intersection, and all cyclists who turned while displaying the right turn on red signal did not stop in front of the signal. 
In the case of the road for bikes in the Pole Mokotowskie Park (object 11), many cyclists were observed who moved along the pavement and entered the road for bikes. Currently, a new road for bicycles has been built in the place of these behaviours.

Opposite direction bicycle lane for cyclists in Mokotowska Street (object 12) was used incorrectly during the period of congestion on the road. Incorrect use of the infrastructure was based on opposite direction bicycle lane in the direction opposite to the one indicated for cyclists. Cycling in this direction should be done by carriageway together with other vehicles. In the absence of congestion on the road, the proportion of such abnormal behaviour was negligible.

The advanced stop line (object 13) is the most complex among the examined infrastructure solutions. It distinguishes as many as 13 different behaviours. Many of them result from the lack of knowledge of the rules of using such an object, as well as from the fear of moving on the road or the lack of patience of cyclists.

The best results - lack of abnormal behaviour - were observed on the road for bikes and pedestrians in Żwirki i Wigury Street (object 2). It is a new bicycle route, designed in accordance with the principles [12] and good practices of designing bicycle routes.

\section{Conclusion}

Research has shown that cyclists' behaviour is strongly dependent on the existing infrastructure. In places where infrastructure is inadequate or lacking, the number of abnormal behaviours is higher. However, well-designed infrastructure reduces, but does not eliminate, abnormal behaviour.

The share of abnormal behaviour is higher in the case of complicated road infrastructure such as a advanced stop line. Cyclists are also prone to irregular behaviour when it comes to speeding up their journeys, such as riding in the wrong direction on a opposite direction bicycle lane. It should be noted that the behaviour of cyclists, even if it is incorrect, shows what are the expectations related to the design of cycling infrastructure. This may be an indication for planning directions of cycling infrastructure development.

The observation is confirmed by the fact that within a year from the study, a bicycle road was built in the Pole Mokotowskie Park, eliminating some of the diagnosed problems. Similarly, a tender was launched for reconstruction of the intersection of Grójecka and Banacha Streets, where $66 \%$ of abnormal behaviours were found, mainly due to cyclists crossing the pedestrian crossing.

The observed abnormal behaviour indicates the need to carry out measures also affecting cyclists, and not only the infrastructure. Educational actions are needed, in particular to draw attention to the problem of driving when a red signal is displayed, as has been the case more often for tracks than for carriageways. It is also necessary to educate children under 10 about cycling, as many of them can be seen on bicycle roads, although according to the regulations [10] they are treated as pedestrians. Policies to punish road traffic offences should also be pursued, as consent to such offences can lead to traffic incidents.

It is advisable to conduct research after reconstruction of some road solutions in order to assess how they affected cyclists' behaviour.

The authors would like to thank the initiator of this research dr. Marek Buda who passed away in 2017. 


\section{References}

1. A. Billot-Grasset, E. Amoros, M. Hours, How cyclist behavior affects bicycle accident configurations?, Transp. Res. Part F Traffic Psychol. Behav. 41 pp. 261-276 (2016). doi:10.1016/J.TRF.2015.10.007

2. L.S. Fruhen, R. Flin, Car driver attitudes, perceptions of social norms and aggressive driving behaviour towards cyclists, Accid. Anal. Prev. 83 pp. 162-170 (2015). doi:10.1016/j.aap.2015.07.003

3. C.-W. Pai, R.-C. Jou, Cyclists' red-light running behaviours: An examination of risktaking, opportunistic, and law-obeying behaviours, Accid. Anal. Prev. 62 pp. 191-198 (2014). doi:10.1016/J.AAP.2013.09.008

4. F. Westerhuis, D. De Waard, Reading cyclist intentions: Can a lead cyclist's behaviour be predicted?, Accid. Anal. Prev. 105 pp. 146-155 (2017). doi:10.1016/J.AAP.2016.06.026

5. N. Waintrub, C. Peña, M. Niehaus, R. Vega, P. Galilea, Understanding cyclist traffic behaviour: Contrasting cycle path designs in Santiago de Chile, Res. Transp. Econ. 59 pp. 228-235 (2016). doi:10.1016/J.RETREC.2016.07.020

6. Warsaw Bicycle Report (in Polish) (Mobility and Transport Policy Office, Warsaw, 2017)

7. The programme for the development of cycle routes in Warsaw by 2020. Final Report (in Polish) (Design and Consulting Office TransEko Sp. j., 2013)

8. M. Buda, O. Bronowska, A. Górka, T. Krukowicz, Speeds of cyclists on dedicated cycling routes (in Polish), Buses - Oper. Technol. Transp. Syst. 12 (2017)

9. K. Cieśla, Behaviour of cyclists on different elements of road infrastructure - Master's thesis, Warsaw University of Technology, Warsaw, 2017

10. The Act on Road Traffic (consolidated text Journal of Laws 2017 item 1260 with later amendments) (Poland, 2017)

11. Regulation of the Minister of Infrastructure of 3 July 2003 on detailed technical conditions for road signs and signals and traffic safety devices and on the conditions for their location on the road, OJ 2003 No. 220 Pos. 2181 as amended (Poland, 2003)

12. Design and implementation standards for the bicycle system of the Capital City of Warsaw (in Polish) (Design and Consulting Office TransEko Sp. j., Warsaw, 2009)

13. Regulation of the Minister of Infrastructure and Development of 3 July 2015 amending the Regulation on detailed technical conditions for road signs and signals and road safety devices and conditions of their placement on roads, OJ 2015, item 1314 (Poland, 2015) 